\title{
Inhaltsverzeichnis
}

Vorwort ....................... 6

I. Abgrenzungen ................... . . . 9

\section{Die Problemlage}

1. Urheberbegriff und Kollektivschaffen . . . . . . . . . . . . 10

2. Filmwerkbegriff und synchronistische Werkeinheit . . . . . 11

3. Verfilmungswerke und Filmwerke . . . . . . . . . . . . . 12

4. Der Bereich der Filmurheberschaft . . . . . . . . . . . . 13

5. Miturheberschaft beim Film . . . . . . . . . . . . . . . 16

6. Tantiemeanspruch und Filmurheberschaft . . . . . . . . . . 18

7. Rechtliche Doppelstellung des Filmherstellers. . . . . . . . 19

8. Urheberrechtliche Stellung der Filmschaffenden . . . . . . . 24

9. Doppeltes Schutzsystem für den Film . . . . . . . . . . 27

10. Methode der Regelung . . . . . . . . . . . . . . 28

\section{Der Urheberbegriff}

1. Wahrung der Rechte beteiligter Urheber . . . . . . . . . . 29

2. Die herrschende Meinung

a) Rechtsprechung . . . . . . . . . . . . . . . . . . . . 30

b) Schrifttum . . . . . . . . . . . . . . . . . . . . . . 31

c) Gesetzesentwürfe . . . . . . . . . . . . . . . . . 32

d) Ausländische Gesetzgebung . . . . . . . . . . . . . 34

e) Berner Ubereinkunft . . . . . . . . . . . . . . . . . . 36

3. Die These von der organisierten Gemeinschaftsarbeit
a) Hoffmann . . . . . . . . . . . . . . . . . . . . . . 37
b) de Boor . . . . . . . . . . . . . . . . . . . . . . . . 38
c) Ruszkowski . . . . . . . . . . . . . . . . . . . . . . . . 40
d) Grunderkenntnisse für die Rechtsform . . . . . . . . . . 41

4. Die Rolle der Technik;

a) Vorgänge der Verwertung von Urheberrechtsgut . . . . 41

b) Vorgänge der Erzeugung von Urheberrechtsgut . . . . . 42

c) Das Filmschaffen . . . . . . . . . . . . . . . . . . . 43

5. Rechtliche Schlüsse

a) Urheber und Filmwerk . . . . . . . . . . . . . . . . . . 45

b) Urheber und Filmhersteller . . . . . . . . . . . . . . . 46

c) Begriff des originären Rechtsträgers . . . . . . . . . . 47

IV. Folgerungen für die Rechtsreform . . . . . . . . . . . . . . . 48 